\title{
Recent Incidence of Paragonimus westermani Metacercariae in Freshwater Crayfish, Cambaroides similis, from Two Enzootic Sites in Jeollanam-do, Korea
}

\author{
Jin-Ho Song', Fuhong Dai ${ }^{2}$, Xuelian Baiं, Tae-Im Kim², Hyun-Jong Yang ${ }^{3}$, Tong-Soo Kim4, Shin-Hyung Cho \\ Sung-Jong Hong ${ }^{2 * *}$ \\ Departments of ${ }^{1}$ Pharmacology, ${ }^{2}$ Medical Environmental Biology, College of Medicine, Chung-Ang University, Seoul 06974, Korea; ${ }^{3}$ Department of \\ Parasitology, Ewha Womans University School of Medicine, Seoul 07985, Korea; ${ }^{4}$ Department of Parasitology and Tropical Medicine, School of \\ Medicine, Inha University, Incheon 22212, Korea; ${ }^{5}$ Division of Vector Analysis, National Institute of Health, Korea CDC, Osong Health Technology \\ Administration, Osong 28159, Korea
}

\begin{abstract}
An epidemiological study was performed to know the recent infection status of Paragonimus westermani metacercariae (PwMc) in freshwater crayfish, Cambaroides similis, from 2 streams in Jeollanam-do, Republic of Korea. Crayfish were collected from creeks in Bogil-do (Island), Wando-gun, and in a creek near Daeheung Temple in Haenam-gun. The infection rate of crayfish with PwMc in Bogil-do was 89.8\%, and the metacercarial burden was 37 PwMc per the infected crayfish. Crayfish in a creek near Daeheung Temple were larger and twice heavier than those in Bogil-do. Of them, 96.5\% were infected with PwMc. An average of 140 metacercariae was found in the infected crayfish, almost quadruple to those of Bogil-do. There was a strong correlation between the number of PwMc and body weight of the crayfish. These results suggest that $P$. westermani metacercariae are still prevalent in crayfish of the 2 regions in Jeollanam-do, Korea.
\end{abstract}

Key words: Paragonimus westermani, metacercaria, freshwater crayfish, Wando, Haenam

Paragonimiasis is a food-borne parasitic disease caused by various species of the lung fluke belonging to the genus Paragonimus, including the type species P. westermani $[1,2]$. It is endemic worldwide as in Asian countries, including Korea, Japan, China, Thailand, and Vietnam. People are mostly contracted by ingesting raw or undercooked freshwater crabs and crayfish, the second intermediate hosts [3]. In the human body, adult flukes lodge near bronchioles forming worm capsules, which cause pulmonary paragonimiasis [2]. The host reactions in response to the mechanical irritation and excretory products of the flukes lead to inflammatory cell infiltrations and granuloma formation. Chronically, there appear purulent, tubercle-like lesion and/or calcification. The flukes can also cause extrapulmonary paragonimiasis, with cerebral paragonimiasis being the most frequent and serious outcomes [4].

Paragonimiasis had previously been rampant in Korea due

\footnotetext{
- Received 21 May 2017, revised 12 June 2017, accepted 13 June 2017.

*Corresponding authors (hongsj@cau.ac.kr)

(c) 2017, Korean Society for Parasitology and Tropical Medicine

This is an Open Access article distributed under the terms of the Creative Commons Attribution Non-Commercial License (http://creativecommons.org/licenses/by-nc/4.0) which permits unrestricted non-commercial use, distribution, and reproduction in any medium, provided the original work is properly cited.
}

to some habits, such as eating raw crabs for food and drinking raw crayfish juice as a folk medicine for the treatment of measles and fever of unknown origin in children. It is now almost eliminated as a result of proper health education and ample supply of therapeutic medicine, praziquantel. Nevertheless, clinical cases of paragonimiasis are reported even nowadays [5-12].

Freshwater crabs and crayfishes harboring P. westermani metacercariae (PwMc) are important sources for human infection. It was recently reported that $32 \%$ of the freshwater crayfish caught in various regions of Korea during 2007-2008 were positive for PwMc, ranging 8-59 PwMc per crayfish with an average of 28 PwMc [13]. Crayfish was known to play enzootically as a source of infection for the reservoir hosts of $P$. westermani [14]. In the present study, we collected a large number of crayfish in creeks to update the infection status with PwMc in Haenam-gun and Wando-gun, and analyzed the correlation of PwMc incidence with the body weight of the crayfish.

Freshwater crayfish (Cambaroides similis, Fig. 1A) were caught in 2 creeks each in 2 regions, namely Bogil-do (Island) in Wando-gun and Daeheung Temple in Haenam-gun, located in the southern coast of Korean peninsula in March 2013. A 

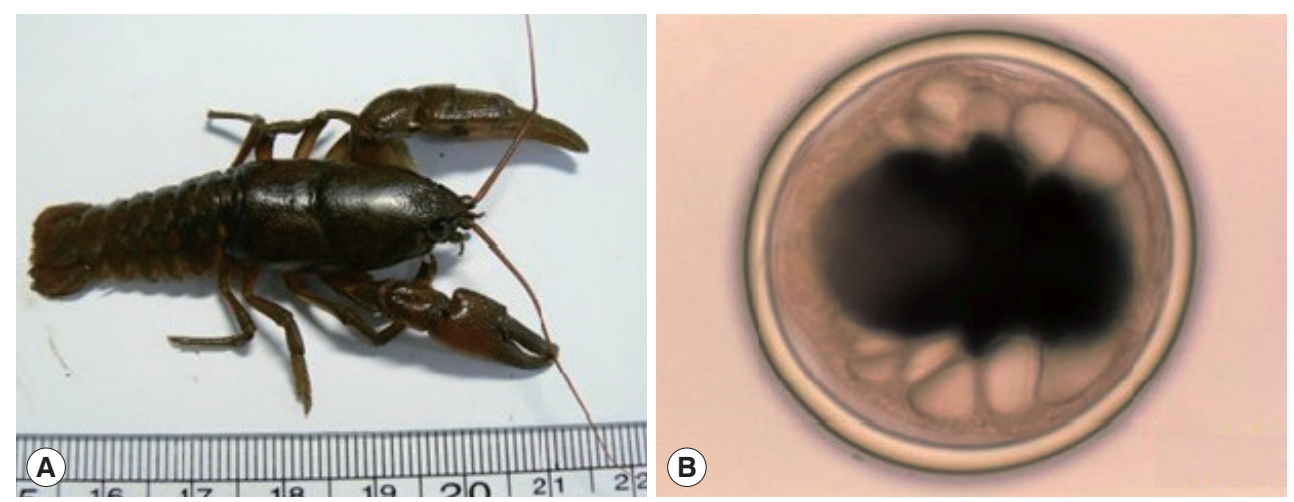

Fig. 1. (A) Freshwater crayfish (Cambaroides similis) caught in a creek near Daeheung Temple, Haenam-gun, Jeollanam-do, Korea. (B) Paragonimus westermani metacercaria isolated from a crayfish.

Table 1. Infection of freshwater crayfish with Paragonimus westermani metacercariae in creeks in Wando-gun and Haenam-gun, Jeollanam-do, Korea

\begin{tabular}{|c|c|c|c|c|}
\hline \multirow{2}{*}{ Location } & \multicolumn{2}{|c|}{ Crayfish } & \multirow{2}{*}{$\begin{array}{l}\text { No. of metacercariae per } \\
\text { infected crayfish }\end{array}$} & \multirow{2}{*}{ Infection rate (\%) } \\
\hline & Length (cm) & Weight (g) & & \\
\hline Bogil Island, Wando-gun & $4.4 \pm 0.1$ & $3.1 \pm 0.2$ & $37 \pm 7.0(1-260)$ & $89.8(53 / 59)$ \\
\hline Daeheung Temple, Haenam-gun & $5.3 \pm 0.1$ & $6.0 \pm 0.3$ & $140 \pm 9.5(1-398)$ & $96.5(82 / 85)$ \\
\hline Total & $4.9 \pm 0.1$ & $4.8 \pm 0.2$ & $100 \pm 7.5(1-398)$ & $93.8(135 / 144)$ \\
\hline
\end{tabular}

Data are presented as mean \pm standard error.
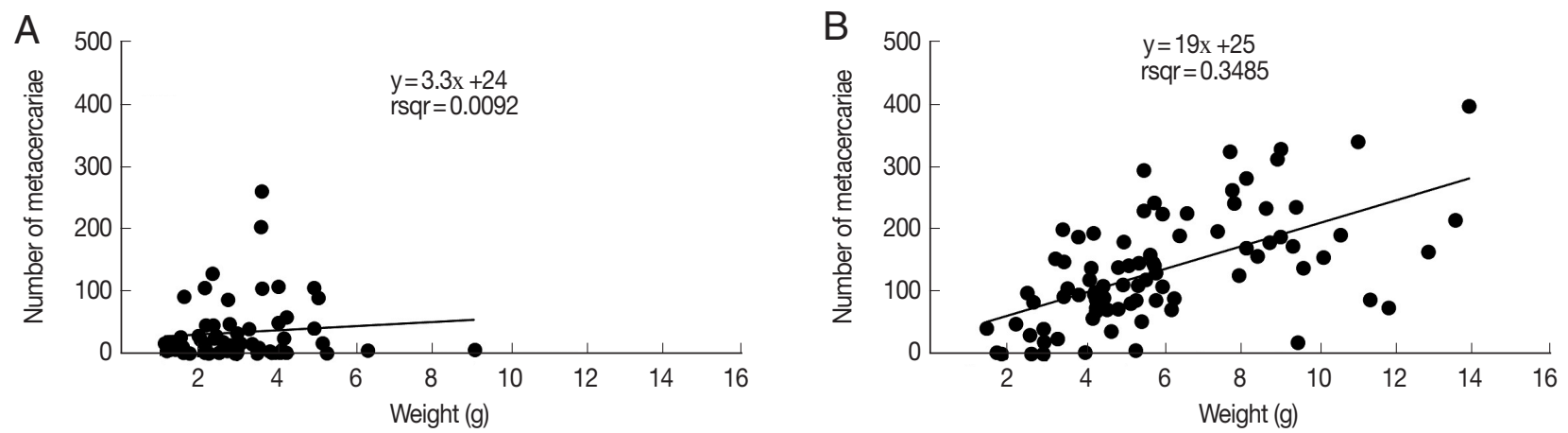

Fig. 2. Plots of the number of Paragonimus westermani metacercariae against the body weight of crayfish. (A) Bogil-do (Island), Wandogun. (B) Daeheung Temple, Haenam-gun. Straight lines are results of a linear regression $(A, P=0.47 ; B, P<0.001)$.

total of 144 crayfish were collected, 59 from Wando-gun and 85 from Haenam-gun. The crayfish was immersed in water for $10 \mathrm{~min}$, taken out, and placed in a dry vessel for another 10 min to adjust water content. The body length from the tip of chelipod to uropod was measured, and the body weight was weighed. It was mashed in a mortar with a pestle and sifted through a $500 \mu \mathrm{m}$-mesh sieve. The filtrate was precipitated and washed several times with physiological saline. The precipitate was examined under a dissecting microscope to find PwMc (Fig. 1B). Simple linear regression was used to assess the correlation between the body weight of crayfish and num- ber of PwMc it harbored.

In Bogil-do, Wando-gun, crayfish showed 89.8\% infection rate with PwMc, and the metacercarial burden of the infected crayfish averaged 37 PwMc, ranging 1-260 PwMc (Table 1). The number of PwMc revealed an increasing tendency along with the body weight of the crayfish. However, a linear regression did not reach a statistical significance $(P=0.47$, Fig. $2 A)$.

Crayfish caught in creeks near Daeheung Temple, Haenamgun were bigger and twice heavier than those in Bogil-do, Wando-gun (Table 1). It was found that $96.5 \%$ of the crayfish were infected with PwMc. An average of 140 (1-398) PwMc 
were found in the infected crayfish, almost quadruple to those of Bogil-do. Moreover, there was a strong correlation between the number of PwMc and body weight of the crayfish $(P<$ 0.001 , Fig. 2B). Overall, $93.8 \%$ of crayfish in creeks in both regions were infected with PwMc, with an average of 100 metacercariae per the infected crayfish (Table 1).

In a survey carried out in Namhae Island, Gyeongsangnamdo in 1966, it was observed that $35 \%$ of the residents were positive for paragonimiasis by intradermal test, and $59 \%$ of the crayfish in this region were infected with PwMc [15]. In Haenam-gun, in 1965-1969, 41\% of residents were positive for the paragonimiasis intradermal test (34\% of the positive responders were also positive for $P$. westermani eggs in their sputum), and $31-50 \%$ of the crayfish were infected with PwMc [16].

With favor of health education and anthelmintic interventions, the incidence of paragonimiasis was dropped drastically and remained under elimination in recent decades in Korea. For example, Gangwha-do (Island), Gyeonggi-do was one of the endemic areas of paragonimiasis. In this region, the infection rate and the average number of PwMc in crayfish were $100 \%$ and 54 in 1973, then decreased to $20 \%$ and 0.6 in 1987, respectively [17].

While the infection rate of PwMc in crayfish and crab decreased nationwide [13], it remained still high in the 2 surveyed regions, Wando-gun and Haenam-gun as shown in the present study. It seems that $P$. westermani life cycle is enzootically stable and even prosperous in these 2 areas. In Bogil-do, Wando-gun and Daeheung Temple area, Haenam-gun, the ecosystem may have some unique infra-structures favorable to perpetuating the sylvatic life cycle of $P$. westermani.

With an economic development, fuel for cooking and heating in rural households had changed from forest woods to fossil fuels. The woods in the forest were left untouched by men and became dense to squeeze out the reservoir hosts, such as raccoons and badgers, to creek sides, and preserved an enzootic cycle there. This suggestion may deserve further surveys in the several neighboring creeks.

The crayfish caught from Daeheung Temple area were much larger and heavier than those from Bogil Island. Given the reason for this difference is unclear, predators, including humans might avidly hunt crayfish in Bogil-do before they fully grew. The number of PwMc increased along with the weight of crayfish in Haenam-gun. The bigger and probably the older crayfish might have eaten more freshwater snails (Semisulcospira libertina), the first intermediate hosts containing the P. wester- mani cercariae, leading the more PwMc accumulated in them.

We report here that the crayfish still have PwMc in certain creeks and streams of Korea. It could be a source of human infection and be a threat to the public health and food safety in Korea.

\section{ACKNOWLEDGMENTS}

This research was supported by the Chung-Ang University Research Grant in 2014.

\section{CONFLICT OF INTEREST}

We have no conflict of interest related to this study.

\section{REFERENCES}

1. Yoshida A, Matsuo K, Moribe J, Tanaka R, Kikuchi T, Nagayasu E, Misawa N, Maruyama H. Venison, another source of Paragonimus westermani infection. Parasitol Int 2016; 65: 607-612.

2. Kim TI, Oh SR, Dai F, Yang HJ, Ha SD, Hong SJ. Inactivation of Paragonimus westermani metacercariae in soy sauce-marinated and frozen freshwater crabs. Parasitol Res 2017; 116: 1003-1006.

3. Tsang KW, File TM, Jr. Respiratory infections unique to Asia. Respirology 2008; 13: 937-949.

4. Chai JY. Paragonimiasis. Handb Clin Neurol 2013; 114: 283-296.

5. Koh EJ, Kim SK, Wang KC, Chai JY, Chong S, Park SH, Cheon JE, Phi JH. The return of an old worm: cerebral paragonimiasis presenting with intracerebral hemorrhage. J Korean Med Sci 2012; 27: 1428-1432.

6. Lee $\mathrm{CH}$, Kim JH, Moon WS, Lee MR. Paragonimiasis in the abdominal cavity and subcutaneous tissue: report of 3 cases. Korean J Parasitol 2012; 50: 345-347.

7. Cho AR, Lee HR, Lee KS, Lee SE, Lee SY. A case of pulmonary paragonimiasis with involvement of the abdominal muscle in a 9-year-old girl. Korean J Parasitol 2011; 49: 409-412.

8. Kim KU, Lee K, Park HK, Jeong YJ, Yu HS, Lee MK. A pulmonary paragonimiasis case mimicking metastatic pulmonary tumor. Korean J Parasitol 2011; 49: 69-72.

9. Kim MK, Cho BM, Yoon DY, Nam ES. Imaging features of intradural spinal paragonimiasis: a case report. Br J Radiol 2011; 84: e72-74.

10. Kyung SY, Cho YK, Kim YJ, Park JW, Jeong SH, Lee JI, Sung YM, Lee SP. A paragonimiasis patient with allergic reaction to praziquantel and resistance to triclabendazole: successful treatment after desensitization to praziquantel. Korean J Parasitol 2011; 49: 73-77.

11. Sim YS, Lee JH, Hong SC, Chang JH, Kang SR, Yang HJ, Sung SH. Paragonimus westermani found in the tip of a little finger. Intern Med 2010; 49: 1645-1648. 
12. Sohn BS, Bae YJ, Cho YS, Moon HB, Kim TB. Three cases of paragonimiasis in a family. Korean J Parasitol 2009; 47: 281-285.

13. Kim EM, Kim JL, Choi SI, Lee SH, Hong ST. Infection status of freshwater crabs and crayfish with metacercariae of Paragonimus westermani in Korea. Korean J Parasitol 2009; 47: 425-426.

14. Shin MH, Min DY. Infection status of Paragonimus westermani metacercariae in crayfish (Cambaroides similis) collected from Bogildo (Islet), Wando-gun, Chollanam-do, Korea. Korean J Parasitol 1999; 37: 55-57.

15. Ahn YK, Suh JK, Lim HC. Survey of paragonimiasis and inter- mediate hosts of Paragonimus westermani in Namhai island (Namhai-Kun, Kyungnam province, Korea). New Med J 1966; 9: 55-59.

16. Chun HB. Epidemiological study on Paragonimus westermani in Hae-nam district, Cholla-Nam-Do, Korea. Yonsei J Med Sci 1970; 3: 174-186.

17. Min HK, Chun KS. Changes of some epidemiologic aspects in a hyperendemic area of paragonimiasis in Kanghwa-gun, Kyonggido, Korea. Ewha Med J 1987; 10: 195-201. 